\title{
Media Permainan Ular Tangga Sebagai Upaya Peningkatan Pengetahuan Ibu Hamil Tentang Stunting di Polindes Gerung Utara Puskesmas Gerung Lombok Barat
}

\author{
Misroh Mulianingsih ${ }^{1}{ }^{*}$, Henny Yolanda ${ }^{1}$, Novita Asri Widiastuti ${ }^{2}$, \\ Hayana Hayana ${ }^{1}$ \\ ${ }^{1}$ Sekolah Tinggi Ilmu Kesehatan Yarsi Mataram, Indonesia \\ ${ }^{2}$ Pusat Kesehatan Masyarakat Gerung Lombok Barat, Indonesia \\ misroh.yarsi@gmail.com*
}

\begin{abstract}
Stunting in children is the impact of nutrient deficiency during the first thousand days of life. So it is necessary to prevent stunting through the fulfillment of nutrition and health services for pregnant women. An effective and fun way to provide health education to pregnant women is through the Stunting Ladder Snake Game as educational health care created by the Ministry of Health of the Republic of Indonesia as an effort to prevent stunting in children. The problem that often occurs is the high rate of stunting due to the lack of knowledge of mothers about stunting and not knowing how to prevent it, so it is necessary for health workers to convey information about stunting in the community, especially pregnant women. This activity was carried out with pregnant women in the work area of the North Gerung Polindes on Wednesday, March 17, 2021, at 09.00 until finished. The purpose of this activity is to increase the knowledge of pregnant women about the prevention of stunting. The method of community service through the game of snakes and ladders. The results obtained are that there is a significant difference in the average value between the knowledge before (pre-test) and after (post-test) doing the game of snakes and ladders. There is an increase in the average value of knowledge of pregnant women after playing snakes and ladders by $26 \%$. We conclude that the game of snakes and ladders is very effective in increasing the knowledge of pregnant women about stunting because it is packaged in a fun game.
\end{abstract}

Keywords: Snakes and Ladders Game; Knowledge; Pregnant mother; Stunting

\begin{abstract}
Abstrak
Stunting pada anak merupakan dampak dari defisiensi nutrien selama seribu hari pertama kehidupan.Sehingga perlu dilakukan pencegahan stunting melalui pemenuhan gizi dan pelayanan kesehatan kepada ibu hamil.Cara yang efektif dan menyenangkan dalam memberikan pendidikan kesehatan kepada ibu hamil yaitu melalui Permainan ular tangga stunting merupakan media edukasi kesehatan yang diciptakan oleh Kementerian Kesehatan Republik Indonesia sebagai upaya dalam mencegah terjadinya stunting pada anak. Permasalahan yang sering terjadi tingginya angka stunting akibat dari pengetahuan ibu yang kurang mengenai stunting dan tidak tahu cara mencegahnya, sehingga dibutukan tenaga kesehatan menyampaikan informasi mengenai stunting dimasyarakat terutama diibu hamil. Kegiatan ini dilaksanakan bersama Ibu hamil di wilayah kerja Polindes Gerung Utara pada hari rabu, 17 Maret 2021 pada jam 09.00 sampai selesai. Tujuan kegiatan ini untuk meningkatkan pengetahuan Ibu hamil mengenai pencegahan
\end{abstract}

How to cite:

Mulianingsih, M., Yolanda, H., Widiastuti, N. A., \& Hayana, H. (2021). Media Permainan Ular Tangga sebagai Upaya Peningkatan Pengetahuan Ibu Hamil Tentang Stunting di Polindes Gerung Utara Puskesmas Gerung Lombok Barat. Jurnal Pengabdian Multidisiplin, 1(1). https://doi.org/10.51214/japamul.v1i1.88 
stunting.Metode pengabdian masyarakat melalui permainan ular tangga.Hasil yang diperoleh adalah terdapat perbedaan yang signifikan nilai rata-rata antara pengetahuan sebelum (pre test) dan setelah (post test) melakukan permaian ular tangga.Ada kenaikan nilai rata-rata pengetahuan ibu hamil setelah bermain ular tangga sebesar 26\%. Penulis menyimpulkan bahwa permainan ular tangga sangat efektif dalam meningkatkan pengetahuan kepada ibu hamil mengenai stunting, karena dikemas dalam sebuah permainan yang menyenangkan.

Kata Kunci: Permainan Ular Tangga; Pengetahuan; Ibu Hamil; Stunting

\section{PENDAHULUAN}

Pada tahun 2017 - 2018, lebih dari setengah balita stunting di dunia berasal dari Asia (55\%). Dari 83,6 juta balita stunting di Asia, proporsi terbanyak berasal dari Asia Selatan (58,7\%) dan proporsi paling sedikit di Asia Tengah (0,9\%) (WHO et al., 2018). Dari hasil riset kesehatan dasar tahun 2018 sebanyak $10,2 \%$ bayi di Indonesia lahir dengan berat badan rendah (< 2500 gram)(Riskesdas, 2018)

Stunting pada anak merupakan dampak dari defisiensi nutrien selama seribu hari pertama kehidupan. Hal ini menimbulkan gangguan perkembangan fisik anak yang irreversible, sehingga menyebabkan penurunan kemampuan kognitif dan motorik serta penurunan performa kerja.Stunting pada balita perlu mendapatkan perhatian khusus karena dapat menyebabkan terhambatnya pertumbuhan fisik, perkembangan mental dan status kesehatan pada anak.Studi terkini menunjukkan anak yang mengalami stunting berkaitan dengan prestasi di sekolah yang buruk, tingkat pendidikan yang rendah dan pendapatan yang rendah saat dewasa.Anak yang mengalami stunting memiliki kemungkinan lebih besar tumbuh menjadi individu dewasa yang tidak sehat dan miskin. Keadaan stunting menyebabkan buruknya kemampuan kognitif, rendahnya produktivitas, serta meningkatnya risiko penyakit mengakibatkan kerugian jangka panjang bagi ekonomi Indonesia(Setiawan et al., 2018).

Berdasarkan dampak buruk Stunting dapat terjadi sebagai akibat kekurangan gizi terutama pada saat 1000 Hari Pertama Kehidupan (HPK). Salah satu cara mencegah stunting adalah pemenuhan gizi dan pelayanan kesehatan kepada ibu hamil. Pada Perpres Nomor 42 Tahun 2013, tanggal 23 Mei 2013, tentang Gerakan Nasional (Germas) Percepatan Perbaikan Gizi pemerintah menjadikan Seribu Hari Pertama Kehidupan (1000 HPK) menjadi prioritas strategi dalam pencegahan stunting (Kementerian Kesehatan Republik Indonesia, 2018).

Salah satu faktor yang dapat menyebabkan terjadinya stunting pada anak juga karena adanya pengaruh dari kurangnya pengetahuan ibu dalam pemberian nutrisi kepada anak (Setiawan et al., 2018). Oleh karena itu diperlukan upaya untuk meningkatkan pengetahuan ibu mengenai stunting. Upaya ini sangat diperlukan, mengingat stunting akan berpengaruh terhadap tingkat kecerdasan anak dan status kesehatan pada saat dewasa. Akibat kekurangan gizi pada 1000 HPK bersifat permanen dan sulit diperbaiki. Oleh karena itu pendidikan kesehatan mengenai pencegahan stunting harus diberikan pada saat 1000 HPK.

Angka Stunting di Lombok Barat terus mengalami penurunan sejak tahun 2008 mencapai 50\%, tahun 2014 turun menjadi 38\%, 36\% pada tahun 2016 dan pada tahun 2020 sejumlah 29\% masih rendah dari Provinsi NTB sejumlah 30\%. Angka ini tidak harus membuat kita evaporia, karena butuh kerja keras dari semua pihak untuk mencapai Lombok barat bebas Stunting di tahun 2024. Peneliti melakukan study pendahuluan dengan metode FGD pada saat kegiatan posyandu dikelompok yang berbeda, sehingga didapatkan bahwa dari 6 ibu terdapat 2 yang dapat menyebutkan definisi serta penyebab dari stunting dan 4 orang lainnya ada yang tidak mengetahui sama sekali mengenai stunting, mereka memiliki prinsip yang penting sehat dan jarang sakit.

Penyuluhan untuk ibu hamil diposyandu diberikan agar dapat meningkatkan pengetahuan 
mengenai stunting serta bisa menurunkan angka stunting. Informasi yang telah didapatkan kepada orang tua tentang stunting harus di cerna dan di ingat oleh orang tua agar pencegahan stunting dapat dilakukan (Rahmawati et al., 2019). Stunting dicegah lewat pemenuhan kebutuhan zat gizi pada ibu hamil sebab makanan bergizi termasuk suplementasi zat gizi (tablet zat besi atau $\mathrm{Fe}$ ) begitu mereka butuhkan, dan kesehatannya pun bisa dipantau. Di samping itu, memonitor pertumbuhan balita di posyandu menjadi hal strategis agar munculnya gangguan pertumbuhan bisa terdeteksi sedini mungkin(Trihono et al., 2015)

Wawasan yang orang tua miliki perihal gejala, efek yang muncul, termasuk penanggulangan stunting bisa menjadi penentu sikap mereka dalam menjaga kesehatan agar stunting bisa tercegah (Rahmawati, 2019). Bila wawasannya bagus, rasa sadar orang tua perihal urgensinya penanganan stunting akan bisa terlihat. Kesadaran itu akan memunculkan perilaku kesehatan, utamanya perihal pencegahan stunting, contohnya lewat pemenuhan zat gizi pada ibu hamil, gizi para anak, penjagaan sanitasi lingkungan rumah, termasuk pola hidup bersih dan menyehatkan (Harmoko, 2017 dalam Yoga \& Rokhaidah, 2020)

Melalui pengabdian masyarakat ini diharapkan dapat meningkatkan pengetahuan ibu dalam pencegahan stunting melalui edukasi kesehatan yang menyenangkan dengan media permainan ular tangga.

\section{METODE}

\section{Waktu Pelaksanaan}

Kegiatan ini dilaksanakan bersama Ibu hamil di wilayah kerja Polindes Gerung Utarapada hari rabu, 17 Maret 2021 pada jam 09.00 sampai selesai. Tujuan kegiatan ini untuk meningkatkan pengetahuan Ibu hamil mengenai pencegahan stunting.Kegiatan ini disusun melalui kesepakatan antara Stikes yarsi Mataram, Pihak Puskesmas, kader dan ibu hamil.Metode yang digunakan adalah dengan memberikan edukasi kesehatan dengan media permainan ular tangga.

\section{Tahapan dan metode pelaksanaan kegiatan}

Metode yang digunakan dalam kegiatan ini adalah, 1) Sebelum pelaksanaan kegiatan dimulai para peserta diberikan penjelasan maksud dan tujuan dari kegiatan, 2) Untuk mengukur pengetahuan ibu hamil tentang stunting sebelum kegiatan dilaksanakan maka dilakukan pre test terlebih dahulu, 3) pelaksanaan permainan ular tangga dilakukan oleh dua (2) orang ibu hamil dengan melemparkan dadu terlebih dahulu dengan tujuan untuk menentukan berapa langkah yang harus dilakukan, setelah itu membacakan tulisan yang ada di gambar dengan keras agar didengar oleh peserta yang lain. Jika bertepatan dengan tangga, maka peserta akan naik ke kotak yang telah ditunjukkan oleh gambar. Gambar yang menunjukkan tangga menunjukkan hal yang positif.Gambar yang menunjukka ular berarti peserta harus turun menuju kotak yang dibawahnya dan hal ini menunjukkan hal yang negative. Pada langkah dikegiatan ini, ibu atau peserta yang lain bisa langsung menanyakan atau langsung berdiskusi sesuai dengan tema yang ada dalam kotak. Contohnya adalah bagaimana pencegahan stunting bisa dilakukan sejak dini (sejak masih remaja).4) Setelah permainan selesai dilakukan diskusi tentang materi sesuai dengan game ular tangga, dan hal lain yang berkaitan dengan tema yang didiskusikan hari ini, para kader juga memberikan pendidikan kesehatan tentang stimulasi gangguan perkembangan anak stunting. 5) Setelah itu dilakukan post test untuk mengevaluasi peningkatan pengetahuan para peserta tentang stunting.

\section{Persiapan Alat dan Bahan}

Persiapan yang dilakukan sebelum kegiatan ini dilakukan adalah mengurus surat dan izin ke pihak Puskesmas dan dusun. Menyepakati hari, jam dan tempat pelaksanaan kegiatan bersama kader dan para peserta (ibu hamil).Mempersiapkan alat-alat untuk tetap menjaga protocol kesehatan, seperti hand sanitizer, 
mencari lokasi agar bisa tetap mejaga jarak pada saat kegiatan berlangsung. Peralatan yang digunakan dalam kegiatan pengabdian masyarakat ini beruba media pendidikan kesehatan metode simulation game Ular tangga berupa spanduk dengan gambar permainan ular tangga dengan ukuran $4 \times 6 \mathrm{~m}^{2}$, dimana dalam setiap kotak terdapat pertanyaan dan jawaban seputar stimulasi perkembangan kognitif yang diberikan pada anak stunting sesuai usia, dadu 2 buah, alat tulis.

\section{Evaluasi}

Evaluasi kegiatan dengan menggunakan kuisioner pre-test dan post-test/

\section{Deskripsi Permainan}

Permainan ular tangga stunting merupakan media edukasi kesehatan yang diciptakan oleh Kementerian Kesehatan Republik Indonesia sebagai upaya dalam mencegah terjadinya stunting pada anak.Permainan ini berisi 36 kolom, dimana kolom nomor 1 merupakan kolom awal permainan dan kolom 36 merupakan akhir permainan. Tujuan permainan ini adalah mencapai kolom 36 sebagai kolom terakhir permainan, dimana setiap kolom akan berisi kebiasaan positf dan negatif, yang akan menjadi bahan edukasi pada permainan ini. Permainan ini menggunakan "tangga" sebagai simbol peningkatan kesehatan apabila melakukan tindakan positif dalam kebiasaan sehari - hari.Sebaliknya, permainan ini menggunakan ular apabila peserta permainan berada pada kolom ekor ular yang menunjukkan tindakan negatif dalam kebiasaan sehari - hari.

Gambar 1. Media Edukasi Kesehatan Ular Tangga Stunting

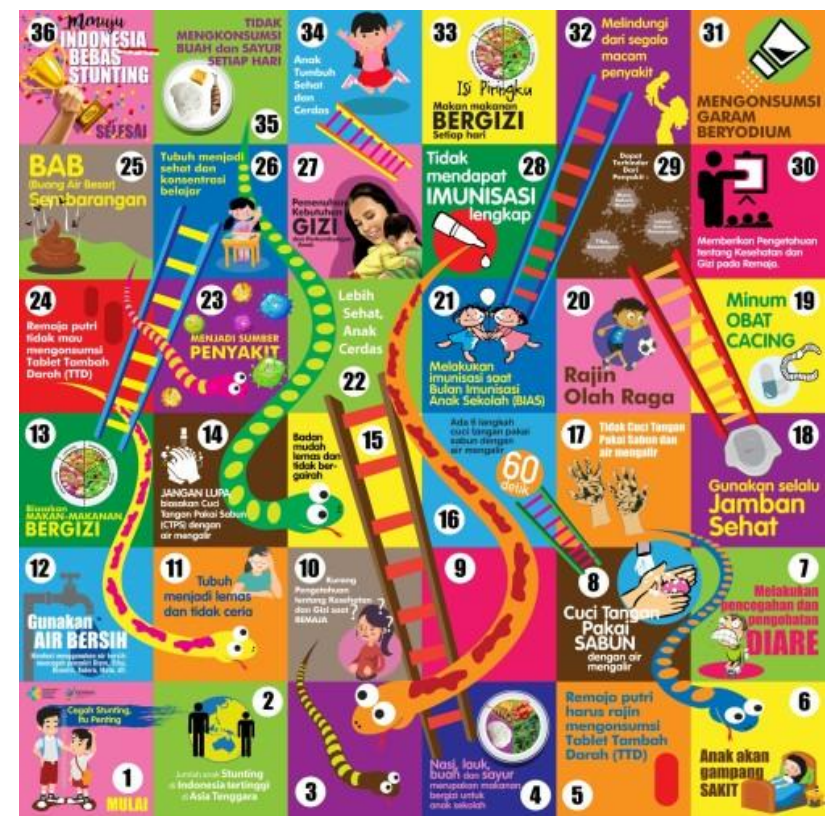

\section{HASIL DAN PEMBAHASAN}

1. Kegiatan 1 pretest

Pertama-tama Ibu hamil yang datang ke polindes diberitahukan bagaimana aturan permainan, sebelum permainan mulai, responden diminta untuk mengisi kuesioner pengetahuan tentang stunting yang berisi 10 pertanyaan. 
2. Saat permainan ular tangga

Setelah ibu hamil mengisi kuesioner, dilanjutkan dengan permainan ular tangga stunting. Sebelum dimulai permainan terlebih dahulu dijelaskan mengenai aturan permainan

3. Posttest

Posttest bertujuan untuk mengukur pengetahuan responden mengenai stunting. Sebagai berikut:

Tabel 1. Hasil Pretest Dan Postest

\begin{tabular}{ccc}
\hline No Reponden & Nilai Pres-test & Nilai Post-test \\
\hline 1 & 5 & 7 \\
2 & 7 & 10 \\
3 & 6 & 10 \\
4 & 6 & 10 \\
5 & 5 & 6 \\
6 & 7 & 9 \\
7 & 5 & 7 \\
8 & 5 & 8 \\
9 & 6 & 8 \\
10 & 5 & 8 \\
Total & 57 & 83 \\
min & 5 & 6 \\
max & 7 & 10 \\
Median & 5,50 & 8,00 \\
Mean & 5,70 & 8,30 \\
\hline
\end{tabular}

Tabel 2. Hasil Pengujian Nilai Beda Pre dan Post-test

\begin{tabular}{lllll}
\hline Variabel pengetahuan & Mean & Standar Deviasi & CL 95\% & P-Value \\
\hline Pretest & 5,70 & 0,823 & $5,11-6,29$ & 0,0001 \\
Postest & 8,30 & 1,418 & $7,29-9,31$ & \\
\hline
\end{tabular}

Berdasarkan tabel diatas, diketahui bahwa dari 10 peserta pengetahuan ibu hamil mengenai stunting saat pretest yang terbanyak yaitu 5 orang nilai 5 (50\%) dengan nilai rata-rata 5,70. Kemudian setalah permainan ular tangga, dilakukan posttest dengan hasil yang signifikan mengalami peningkatan pengetahuan yang terbanyak yaitu 3 orang nilai 10 (30\%) dengan nilai rata-rata 8,30 sehingga mengalami peningkatan sebanyak $26 \%$. Pengetahuan ibu hamil mengalami peningkatan karena saat permainan ular tangga mereka mendapatkan pengetahuan dengan cara yang berbeda dari biasanya melalui permainan yang asik dan menyenangkan.

Pengkuran pengetahuan pengetahuan dilakukan dengan cara memberikan kuesioner pada saat pretest dan postes yang merupakan cara yang mudah dalam mendeteksi pengetahuan ibu hamil mengenai stunting didaerah tertentu yang bertujuan untuk mengetahui tingkatan pengetahuan ibu hamil menngenai stunting (Zulfita et al., 2020).

Pengetahuan merupakan aspek yang sangat penting dalam terbentuknya tindakan seseorang.Sehingga jika pengetahuan seseorang itu baik semakin baik pula responden dalam memberikan nutrisi yang baik untuk anak-anaknya dalam mencegah stunting dan perubahan pengetahuan responden dapat dipengaruhi oleh pemberian pendidikan kesehatan melalui permainan ular tangga (Soekidjo 
Notoadmodjo, 2014)

Proses penerimaan informasi dengan permainan ular tangga akan memiliki intensitas yang tinggi untuk mempersepsikan sebuah informasi dibandingkan dengan melakaukan ceramah. Saat para ibu hamil memainkan ular tangga, indra yang digunakan selain mata adalah telinga. Semua panca indra merupakan jalur penerimaan informasi ke otak, semakin banyak indra yang digunakan dalam penyampaian informasi maka akan semakin banyak infromasi yang akan diterima dan yang akan disimpan. Saat ibu hamil melakukan permainan ular tangga ini mereka akan membaca pertanyaan atau perintah dan melihat gambar yang terdapat dalam pemainan ular tangga. Kemampuan seseorang untuk bisa mengingat suatu informasi, akan meningkat lebih tinggi bila mempelajari suatu materi dengan metode membaca, karena dengan membaca kemampuan mengingat akan meningkat, dalam permainan ular tangga ini para ibu hamil akan membaca tulisan yang tertera dimasing-masing kotak permainan ular tangga sehingga akan meningkatkan kemampuan mengingat terhadap masalah stunting . (Arini et al., 2020).Permainan ular tangga ini dilakukan dalam kelompok kecil 10 orang sehingga dengan jumalh anggota pemain yang sedikit maka suasana dangat mudah dikendalikan dan tidak akan terdistraksi dengan hal-hal yang dapat memcahkan konsentrasi sehingga informasi yang diterima dapat mudah dicerna (Afandi, 2009 dalam Arini et al., 2020)

Permainan ular tangga dapat merangsang seseorang untuk mengembangkan kemampuan kognitif, moral, mental emosional dan social, serta psikomotor (Nurzihan \& Permatasai, 2019). Dan merupakan salah satu mediayang digunakan dalam kegiatan belajar mengajar dimana permainan ular tangga dapat memuat informasi-informasi penting yang terdapat di petak-petaknya.Secara psikologis, ular tangga terbukti dapat meningkatkan kemampuan untuk berinteraksi dengan kehidupan social (Chabib et al., 2017). Beberapa penelitian juga menyebutkan bahwa simulasi permaianan ular tangga efektif dalam meningkatkan pengetahuan mengenai materi kesehatan (Nurzihan \& Permatasai, 2019).

\section{KESIMPULAN}

Permainan ular tangga merupakan salah satu metode pembelajaran kooperatif dimana memberikan kesempatan kepada ibu hamil untuk melakukan interaksi dan berpartisipasi aktif selama kegiatan berlangsung sehingga dapat mengembangkan secara mandiri melalui proses berpikirnya dalam mengolah informasi, sehingga metode pendidikan kesehatan dengan permainan ular tangga sangat efektif sekali dalam meningkatkan pengetahuan untuk para ibu hamil.

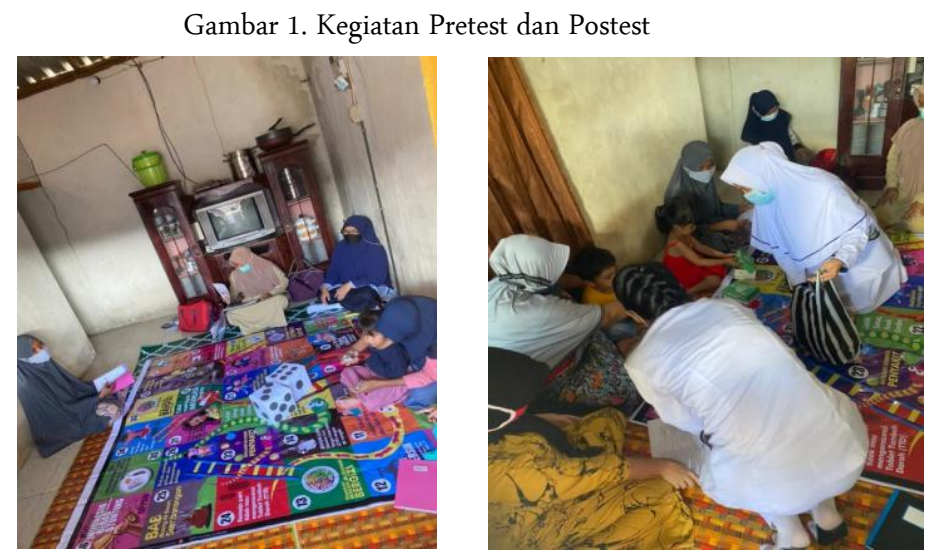



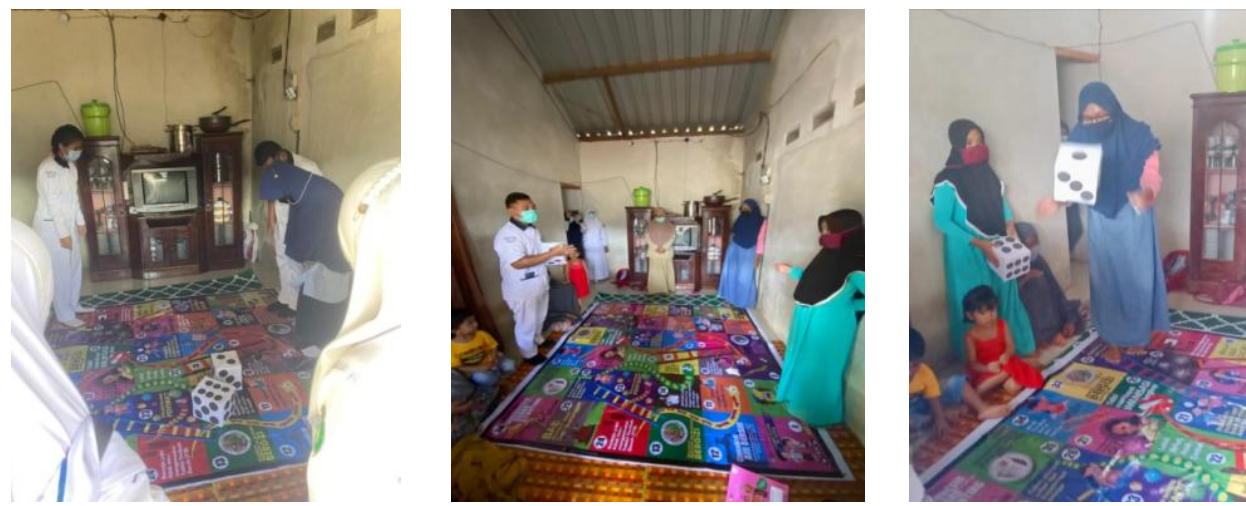

\section{UCAPAN TERIMAKASIH}

Terimakasih yang tidak terhingga kami sampaikan kepada 1) Pihak puskesmas gerung yang telah memberikan izin dan memberikan support kepada kami, 2) Stikes Yarsi Mataram yang telah memberikan izin, 3) Pihak dusun gerung utara, 4) Bidan desa polindes gerung utara beserta kader, 5) Mahasiswaku tercinta yang membantu semua persiapan dari awal, dan 7) semua pihak yang sudah membantu terlaksananya kegiatan ini yang tidak dapat kami sebutkan satu persatu, semoga Allah SWT membalasnya.

\section{DAFTAR PUSTAKA}

Arini, D., Ernawati, D., \& Saidah, Q. ila. (2020). Pengaruh Penyuluhan Metode Simulasi Game pada Kader Dalam Memberi Stimulasi Kognitif Anak Stunting diwilayah Puskesmas Kenjeran. Jurnal Pengabdian Kesehatan, 3(1), 41-49.

Chabib, M., Tri Djatmika, E., \& Kuswandi, D. (2017). Efektivitas Pengembangan Media Permainan Ular Tangga Sebagai Sarana Belajar Tematik SD. Jurnal Pendidikan, 2(7), 910-918.

Kementerian Kesehatan Republik Indonesia. (2018). Warta Kesmas - Cegah Stunting Itu Penting. Warta Kesmas, 1-27.

Nurzihan, N. C., \& Permatasai, O. (2019). Peningkatan Pengetahuan Remaja Tentang Pedoman Gizi Seimbang dengan Permainan ular Tangga Gizi DI SMP PGRI 1 Surakarta. 13(9), 13-15.

Rahmawati, A., Nurmawati, T., \& Sari, L. P. (2019). Faktor yang Berhubungan dengan Pengetahuan Orang Tua tentang Stunting pada Balita. Jurnal Ners Dan Kebidanan (Journal of Ners and Midwifery), 6(3), 389-395. https://doi.org/10.26699/jnk.v6i3.art.p389-395

Riskesdas, K. R. (2018). Hasil Utama Riset Kesehatan Dasar (RISKESDAS). 44(8), 1-200. https://doi.org/10.1088/1751-8113/44/8/085201

Setiawan, E., Machmud, R., \& Masrul. (2018). Faktor-Faktor yang Berhubungan dengan Kejadian Stunting pada Anak Usia 24-59 Bulan di Wilayah Kerja Puskesmas Andalas Kecamatan Padang Timur Kota Padang Tahun 2018. Jurnal Kesehatan Andalas.

Trihono, A., Tjandraini, D. H., Irawati, A., Utami, N. H., Tejayanti, T., \& Nurlinawati, I. (2015). Pendek (Stunting) di Indonesia, Masalah dan Solusiya: Badan Penelitian dan Pengembangan Kesehatan.

WHO, UNICEF, \& Group, W. B. (2018). Levels and Trends in Child Malnuutrition. 1-16.

Yoga, I. T., \& Rokhaidah. (2020). Pengetahuan Ibu Tentang Stunting Pada Balita Di Posyandu Desa Segarajaya. Indonesian Journal of Health Development, 2(3), 183-192. 
https://ijhd.upnvj.ac.id/index.php/ijhd/article/view/74

Zulfita, Refti, Y., Busta, S. wahyu, \& Yulastri, U. (2020). Ular Tangga Stunting di TK Buah Hati Kenagarian Kasang Kabupaten Padang Pariaman. Jurnal Kretaivitas Pengabdian Kepada Masyarakat (PKM), 3(April), 52-61. 